\title{
Ecological Security, Agricultural Safety and Utilization of Agricultural Water Resources
}

\author{
Wu Qiong' Liu Yu \\ School of Management, Wuhan Institute of Technology, Wuhan, P.R.China, \\ 430205 \\ (Email:wuqionglady@163.com, lyu429@163.com)
}

\begin{abstract}
In this paper, the standard research method is used to define the concept and connotation of the agricultural water resources ecological security and agricultural safety, to analyze the influence between the ecological security, agricultural safety, and the utilization efficiency of water resources, the change of the relation between ecological security and agricultural security can be divided into three stages according to Keshena's model, considering the status of China's agricultural water resources utilization, the current state of relationship between the ecological security and agricultural safety is in the first stage, the goals of agricultural water ecological security and agricultural safety conflict, intensive exploitation and utilization mode of water resources can be applied to solve the conflict.
\end{abstract}

Keywords: ecological security, agricultural safety, utilization mode of agricultural water resources

\section{Introduction}

In China, the agricultural sector is one of the largest water resources consumption sector, the utilization efficiency of agricultural water is very low due to the low efficiency management of water resources in Chinese surface water irrigation systems, on the whole, only about $40 \%$ water resources is eventually absorbed by crops in China surface water system. Other studies estimate the waste of water resource in China is more serious than that mentioned above. For this, the agricultural water resources should make full protection and reasonable utilization of, in order to enhance agricultural safety. In fact, a similar situation exists in many developing country, such as in Africa, due to the lack of water resources, agricultural production can not meet the needs of the population in food, leading to the serious threat of agricultural development; in turn, overexploitation and irrational use of resource in order to ensure food safety forms the major threats to the ecological security. If the constraint mechanism of environmental resources use behavior lacks, the ecological and agricultural safety problem will inevitably appear. Jules Pretty illustrates this point of view from another side, thinks" zoology agriculture mode can not only improve productivity, but also can effectively use water resources, improve soil quality, reduce the amount of chemical fertilizer, help to promote the sustainable development of agriculture". Therefore, exploring various methods to ensure the quality of the environment, maintaining the ecological safety, thereby protecting basic conditions need to ensure agricultural safety, will become the current practice of various countries.

\section{Related Concepts}

\subsection{The ecological security of agricultural water resources}

(1) The connotation. The ecological security of agricultural water resources means that water resources system can guarantee the water quantity and quality required by agricultural development, and this system can make sure that agriculture is not threatened, there is no danger, harm and loss [1], at the same time, the minimum water required by water ecological system should be guaranteed, and human beings can not occupy overabundance ecological water to wreck ecosystem [2].

(2) The extension. Food security, agriculture ecological environment safety, agricultural economic security, rural social security caused by ecological security, as well as the whole social economy and ecological security caused by the subsystem, and even political stability, national security.

\subsection{Agricultural safety}


Agricultural safety is the concept that is being developed, deepened and enriched. Because of the different position in national economy at different period, the connotation of agricultural safety is not the same. Through teasing the concepts we find that agricultural safety is more wide than commissariat safety and food security, covering both.

(1) The connotation. Defined by the Statistical Science Research Institute, agricultural safety mean that agriculture can basically meet the needs of the society's increasing demand for food, and keep developing[3]. Considering the background of citification, accelerating and increasing in the context of population, the quantity change of grain, oil, meat, eggs, milk, fruits, aquatic products and grain self-sufficient rate, as well as the measures used to ensure agriculture production system's sustainable development are utilized to evaluate agricultural security condition in the following paper.

(2) The extension. Closely related to sustainable supply of natural resources, environment and the ecological, of which the most important one is the safety of agricultural water resources and land resources, the sustainable development of agriculture is the precondition to achieve agriculture security status, water and soil resources is an indispensable element in agricultural production.

\section{Ecological Security and Agricultural Se- curity Relations: Conflict and Unity}

Found from discriminating the concepts, ecological security and agricultural safety is unity of opposites.

One way, In order to protect the two security at the same time, the limited water resources must be allocated among ecological water and agriculture use water (not to consider industrial water).under the restriction of a certain technical level and the limited water resources constraint ecological security and agricultural safety is opposite. It is also the core problem about using agricultural water resources.

Another way, ecological security and agricultural safety are unitive. Ecological security is the foundation of agricultural safety, and agricultural safety can promote the degree of water resources ecological security. If region ecological environment worsen, it will seriously affect the security level and ability of sustainable development of regional ecological, agricultural ecological security level will dropped considerably, thus agriculture production will be affected. Therefore, the safety of regional natural resource's quantity and quality is the foundation of agricultural safety. If agricultural is in a safe state, food reserves and the supply is adequate, commissariat price is stable.

\section{The Influence of Ecological security, Safe- ty of Agriculture and the Use Efficiency of Agricultural Water}

\subsection{The relationship of agricultural water resources and agricultural security}

Sustainable supply of water resources can ensure agricultural safety effectively. According to "China Daily" report, in 1995, due to depletion of the Yellow River, Shandong Province, commissariat output reduced $2700000 \mathrm{~T}$, which can meet the needs of 9000000 people. In 1997, the cutoff time of Yellow River is 2 times the time in 1995, commissariat reduction in production is more serious. According to the forecast, to 2030 or so, the population of our country will peak at 1600000000 , gross amounts of countrywide commissariat demand will exceed $700000000 \mathrm{t}$ [4].The huge population base increases the demand for food, at the same time, along with the increase of people's living level and improvement of people's diet structure, the daily consumption of animal food increases, it will indirectly increase the demand for food. In this case, it is how to make full use of the water resource effectively that becomes the key that can solve the problem of water resources and food security. As one of the main factors that can solve the food problem, irrigation water accounts for $90.2 \%$ of the total water quantity used by agriculture, In 2000, for example, the average output of paddy of irrigation farmland is about $460 \mathrm{~kg}$ per mu, the average output of other commissariat crop of irrigation farmland is about $350 \mathrm{~kg}$ per mu, the average output of commissariat crop fed by rain is only $140 \mathrm{~kg}$ per mu, the output of commissariat of irrigation farmland is 1-3 times the output of commissariat of non-irrigation farmland. In china, $70 \%$ of countrywide total commissariat output, $80 \%$ of cotton yield, and more than $90 \%$ of vegetable total output were produced by irrigation farmland that occupies less than $50 \%$ area of countrywide farmland [5].

As the water consumption rises substantially, waste water discharge increases accordingly, agricultural production and food safety will be 
threat by a mass of waste water. According to the survey, in 2007, the length of the river whose water quality according with and superior to class III accounted for 59.5\% of the countrywide $140000 \mathrm{~km}$ rivers, it is the Yellow River, Liaohe, Huaihe, Songhua River and Haihe River that have poor water quality, the river length whose water quality according with and superior to class III accounted for 47\%-28\%; The area of the lake whose water quality according with and superior to class III accounted for $48.9 \%$ of 44 lakes. According to nutrition state, 27 lakes were evaluated to be in eutrophic state among the 43 major lakes. According to the data provided by the United $\mathrm{Na}-$ tions Food and Agriculture Organization, in China the length of the main rivers is 50000 $\mathrm{km}, 80 \%$ of which has degenerated seriously, and do not meet the quality standard of fishery water. The toxicant let by city and upstream enterprises including paper mills, tanneries, refineries and chemical plants pollutes the limited water resources, brings about water shortage in many areas.

\subsection{The relationship of agricultural water resources utilization and ecological security}

The impact that Agricultural development bring to ecological security must be looked on dialectically, on one hand, compared with the industry, agriculture has ecological conservation function, including water conservation, soil conservation, environment purification, carbon fixation and oxygen supply, and biological diversity, including rainwater store, water purification, flood control and other functions closely related to water resources. Ecological conservation function of agriculture brings survival and living environment of human great benefit, which can not be measured accurately, but has huge utility. On the other hand, the quantity and quality of water resource can be affected by agricultural development path and resource utilization patterns irreversible, thereby endangering the ecological security. The ecological system has inherent self restoration "basic function" and system "supply function". If the supply function of ecological system has been exploited and utilized overly, the basic function of ecological system will degenerate or be bankrupt in, and restrict system supply function. Chinese rural environmental degradation mainly displays in: soil erosion, land desertification, forest area and quality decline, grassland degradation and loss of biodiversity. Undeserved growth mode causes environmental pollution, resource dry rot. The degeneration of the environment caused by human activities is the important reason of ecosystem degeneration.

Because canal system water and field water were not utilized fully, a mass of agricultural water is wasted in China. Most of China's farmland still rely on channel diversion for irrigation, a few rely on the old dust channel, and a part of the water diversion project has not been repaired and become ageing, resulting in a substantial increase in the loss of water transportation. According to concerning sectional investigation and statistics, the use coefficient of canal system water is only $30 \%-40 \%$, namely water loss rate is high up to $60 \%-70 \%$; while this index of the developed countries is only $20 \%-30 \%$, due to the widespread use of concrete and pipeline of a high standard in the course of water transportation. Because at present the most field engineering facilities are not enough in our country, or land is rough, resulting in a large number loss or waste of field water, our field water loss rate is generally high around $20 \%$. If we have enough field engineering facilities and flat land, the loss rate of field water can be lowered to below $10 \%$. The extensive mode of water use make water natural resources under increasingly heavy burden, China-Japan Joint survey report about China's agricultural prospects problems pointed out, in almost all Chinese plain area, groundwater level decline problem has appeared.

The deterioration of water quality is related to many other factors besides utilization of water resources. First of all, the water environment is related to the use of land, the degradation of land environment and the deterioration of water environment are mutually reinforcing. Agricultural nitrogen loss caused by land cover change is a major source of ground water contamination, farmland runoff and sewage discharge is the reason causes high content nitrate in deep well water. Secondly, dumping, filling and burying, setting on fire production and living waste is another source of ground water contamination. Under the effect of rain, large amount of filtrate of waste and garbage that is piled up everywhere discharged into a body of water, or directly into the river. Once again, along with farmland drainage, the chemicals discharged into rivers and lakes, the residual chemicals that have evaporated into the atmos- 
phere discharged into water with rain. In 2005 China fertilizer consumption amounts reach $300 \mathrm{~kg} / \mathrm{ha}$, far more than the upper limit of fertilizer use safety, namely international standard $225 \mathrm{~kg} / \mathrm{ha}$, set up to prevent water pollution. Finally, waste residue let by livestock and poultry farm, slop caused by cleaning the body of livestock and poultry, the land and apparatus of livestock farm is also the source of ground water contamination. From a practical point of view, China's non-point source pollution problems caused by large-scale intensive livestock breeding are still very prominent, the rat of sewage treatment is low, waste comprehensive utilization rate is not high. For example, the rate of sewage treatment of scale breeding farm was only $35 \%$, waste utilization rate was $59.68 \%$ in Guangdong.

\subsection{The interaction of pairs of safety and uti- lization efficiency of agricultural water re- source}

Typically, in the initial stage of economy development, natural resources is the main factor invested to promote economic growth, economy grows at the cost of great consumption of resources. With the development of diversification of economy, the introducing of new technology and new policy, the country (region) can limit the action might damage the environment sufficiently. Finally, resource utilization will enter the third stage, the extraction rate of natural resources is lower than it in the condition of sustainable use at this stage, namely, the use efficient of natural resources is high. The relationship between the utilization of natural resources and economic development at three stages can be explained by Keshena's model, as shown in Figure1, along with the economic development, resources utilization will experience the state beyond the sustainable use of resources (locus of state A), "prevention" development phase (locus B), eventually reach the sustainable status (locus C).

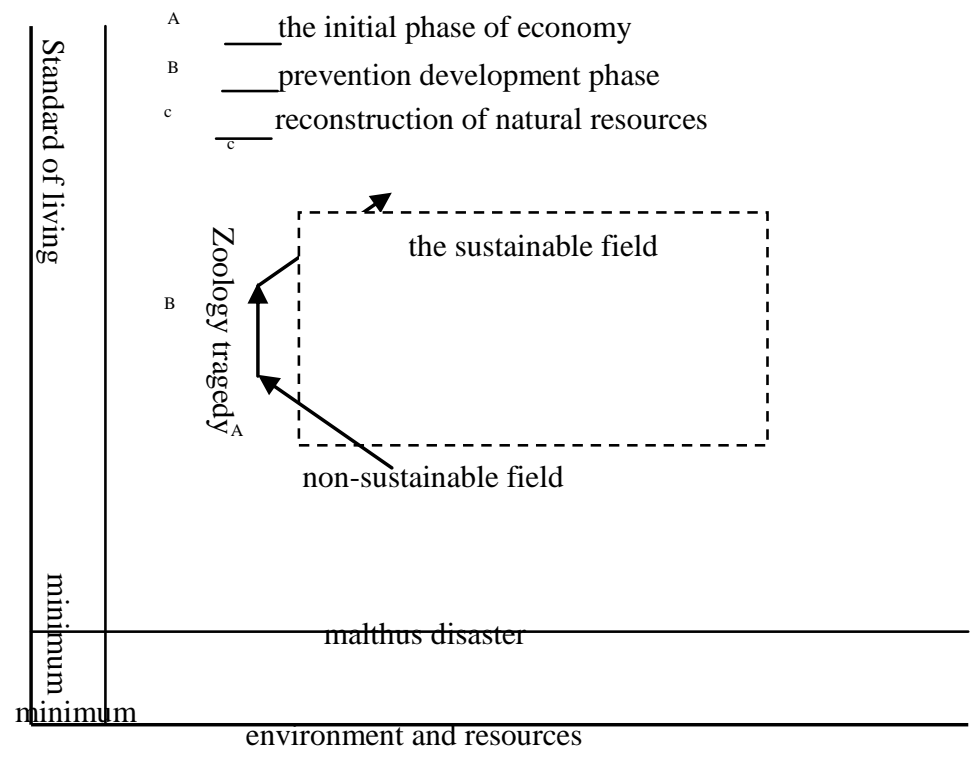

Figure 1 Relation of Resource Utilization and Economic Development

According to Keshena's model, the change of the relationship between the ecological security and agricultural security can be divided into three main stages:

The first phase, agriculture is safe, ecological quality decline. Utilization of water resources is a connectionist links ecological security and agricultural security. When the water resources utilization intensity is lowered, a good ecological environment can be maintained, but if industrial water is deficient, agricultural security can not be ensured. In this case, considering survival demand the human are rational, and will guarantee the demand for agricultural water to achieve the target of agriculture safety.

Because occupy the ecological water, extensive exploitation and utilization patterns of wa- 
ter resources can meet the industry demand for water resources in short term, but will destroy the structure of water resource system itself in long term, and damage the service capacity of water resources system for human, thus can not meet the requirements for water resources that maintain agricultural safety.

The second phase, agricultural safety rises stage by stage, ecological quality remains unchanged. Extensive utilization of water resources ensures agricultural safety but means to makes ecological quality decline gradually. Then, will ecological security be difficult to achieve? That depends on the water resource utilization mode, which depends on the level of technology and management used to utilize the water resources. Extending the time span, considering the effect of water resources utilization, inappropriate use pattern may maintain only agricultural safety, even can maintain on one. With the introduction of new technology, the regional behavior and activities destroy the environment can be limited sufficiently.

The third phase, agricultural safety rises stage by stage, ecological environment is improved gradually. This is the ideal state and the goal pursued by social and economic development. At this stage, the water extraction rate is below the rate of the sustainable state of water resources, namely the utilization efficiency of agricultural water resource is high in this state, only reaching this stage, the target of social sustainable development may be realized.

According to the status of China's agricultural water resources utilization, the current state of relationship between the ecological security and agricultural safety is in the first stage, agricultural safety can be ensured, but ecological quality drops ceaselessly, the goals of agricultural water ecological security and agricultural safety conflict. Improving utilization efficiency of agricultural water resource is an effective path to solve conflict, namely changing the current extensive exploitation and utilization patterns of water resources, forming intensive exploitation and utilization mode of water resources.

\section{Conclusion}

This paper first defines the concept and connotation of agricultural water resources ecological security and agricultural safety, and then discusses the relationship between the agricultural water resources utilization patterns and ecological security level, and the function of agricultural water resources to agriculture security. According to the interaction relationship between utilization of agricultural water resources, ecological security and agricultural safety, the paper points out intensive exploitation and utilization mode of water resources can be applied to ensure both ecological security and agricultural safety.

\section{References}

[1]Liu Buchun, et al. The Definition, Connotation and Extension of Agricultural Water Resources Security[J]. Agricultural Sciences in China, 2006, 39 (5): $947-$ 951 (In Chinese)

[2] Jia Shaofeng, Zhang Junyan, Zhang Shifeng. Regional Water Resources Stress Index and Water Resources Security Evaluation Index System[J]. Progress in Geography, 2002, 21 (6): 538-545 (In Chinese)

[3] Institute of Statistical Science. The Safety Problem of Agriculture and Food[J]. Statistical Research, 2002 (10): 17-20 (In Chinese)

[4] Deng Hongdi. The land resource security in China: challenges and countermeasures[C]. 21cn Land Science and the Development of Economy and Society -Chinese Land Society 2003 Annual Academic Symposium. Xinjiang 2003 ( In Chinese)

[5] Shen Zhenrong, He Weicheng. Evaluation, Existing problems and Solving ways Of Chinese agricultural water[J]. Journal of Natural Resources, 1996, 11 (3): 221-230 (In Chinese) 